\title{
Loss of IRF-4-binding protein leads to the spontaneous development of systemic autoimmunity
}

\author{
Jessica C. Fanzo, ${ }^{1}$ Wen Yang, ${ }^{1}$ So Young Jang, ${ }^{1}$ Sanjay Gupta, ${ }^{1}$ Qinzhong Chen, ${ }^{1}$ \\ Ayesha Siddiq, ${ }^{1}$ Steven Greenberg, ${ }^{1,2}$ and Alessandra B. Pernis ${ }^{1}$
}

1Department of Medicine and 2Department of Pharmacology, Columbia University, New York, New York, USA.

\begin{abstract}
IFN regulatory factor 4-binding (IRF-4-binding) protein (IBP) is a novel type of activator of Rho GTPases that is recruited to the immunological synapse upon TCR stimulation. Here we demonstrate that loss of IBP leads to the spontaneous development of a systemic autoimmune disorder characterized by the accumulation of effector/memory $\mathrm{T}$ cells and $\mathrm{IgG}^{+} \mathrm{B}$ cells, profound hypergammaglobulinemia, and autoantibody production. Similar to human systemic lupus erythematosus (SLE), this syndrome primarily affects females. T cells from IBP-deficient mice are resistant to death in vitro as well as in vivo and exhibit selective defects in effector function. In the absence of IBP, T cells respond suboptimally to TCR engagement, as demonstrated by diminished ERK1/2 activation, decreased c-Fos induction, impaired immunological synapse formation, and defective actin polymerization. Transduction of IBP-deficient T cells with a WT IBP protein, but not with an IBP mutant lacking the Dbl-like domain required for Rho GTPase activation, rescues the cytoskeletal defects exhibited by these cells. Collectively, these findings indicate that IBP, a novel regulator of Rho GTPases, is required for optimal T cell effector function, lymphocyte homeostasis, and the prevention of systemic autoimmunity.
\end{abstract}

\section{Introduction}

Effective immune responses require the appropriate activation and differentiation of peripheral $\mathrm{T}$ cells. These processes need to be followed by the timely elimination of the responding $\mathrm{T}$ cells in order to restore $\mathrm{T}$ cell homeostasis $(1,2)$. Defects in the appropriate regulation of $\mathrm{T}$ cell function and survival can lead to the onset of autoimmune disorders $(3,4)$. T cell abnormalities are crucial for the development of systemic lupus erythematosus (SLE), an autoimmune disorder characterized by hypergammaglobulinemia, autoantibody production, and multiorgan involvement, that predominantly affects females (5-7). T cells from lupus patients have been demonstrated to exhibit a variety of biochemical, functional, and homeostatic defects, including decreased ERK1/2 activation, increased expression of the repressor cAMP response element modulator (CREM), defective production of IL-2, and impaired apoptotic responses (8). The molecular mechanisms responsible for the $\mathrm{T}$ cell defects in SLE are, however, not fully understood.

The expansion and differentiation of $\mathrm{T}$ cells is initiated by engagement of the TCR, which triggers a complex cascade of biochemical events as well as a profound reorganization of the actin cytoskeleton $(9,10)$. TCR-mediated cytoskeletal remodeling is necessary for the assembly of the immunological synapse, a specialized interface between the $T$ cell and the antigen-presenting cell, which subserves multiple functions, including the optimal delivery of TCR-induced signals $(11,12)$. Actin cyto-

Nonstandard abbreviations used: ANA, antinuclear antibody; AP-1, activating protein-1; CREM, cAMP response element modulator; dsDNA, double-stranded DNA; GEF, guanine nucleotide exchange factor; IBP, IRF-4-binding protein; IRF-4, IFN regulatory factor 4; KLH, keyhole limpet hemocyanin; LAT, linker for activation of T cells; NP, 4-hydroxy-3nitrophenylacetyl; PNA, peanut agglutinin; RV, retroviral; SEB, staphylococcal enterotoxin B; SEE, staphylococcal enterotoxin E; SLAT, SWAP-70-like adapter of T cells; SLE, systemic lupus erythematosus.

Conflict of interest: The authors have declared that no conflict of interest exists. Citation for this article: J. Clin. Invest. doi:10.1172/JCI24096. skeletal remodeling requires the activity of the Rho family of GTPases, which includes Rac and cell division cycle 42 (Cdc42), and these GTPases are essential for the appropriate development and function of T cells $(13,14)$. Rho GTPases not only regulate cytoskeletal reorganization but also modulate gene expression via their ability to activate MAPK (15). A major class of proteins responsible for the activation of Rho GTPases is the diffuse $B$ cell lymphoma (Dbl) family of guanine nucleotide exchange factors (GEFs) (16). One member of this family, Vav, plays a key role in $\mathrm{T}$ cell cytoskeletal reorganization, and its deficiency leads to profound developmental and functional defects in $\mathrm{T}$ cells $(17,18)$. The control of Rho GTPase-mediated responses is, however, complex and likely to involve the participation of additional types of regulators (19).

We recently cloned a protein called IFN regulatory factor 4binding (IRF-4-binding) protein (IBP), which exhibits significant homology with SWAP-70, a novel type of Rac GEF $(20,21)$. SWAP-70 is expressed in mature B cells, but not in T cells, and SWAP-70-deficient mice exhibit defects in IgG1 and IgE production $(22,23)$. In contrast, IBP is highly expressed in T cells and, upon TCR engagement, is rapidly tyrosine phosphorylated and recruited to the immunological synapse in a manner that is dependent on the activities of both Lck and PI3K $(20,24)$. These TCR-mediated signals furthermore control the ability of IBP to activate Rac and Cdc42. Murine IBP is identical to SWAP-70like adapter of T cells (SLAT), which was identified during an analysis of transcripts that are differentially expressed in Th2 cells (25). The physiologic role of this novel molecule is at present unknown. Here we report that disrupting the expression of IBP leads to defects in the homeostasis and function of peripheral $\mathrm{T}$ cells and, with age, to the spontaneous development of a lupuslike syndrome. These data thus support the notion that IBP is a novel regulator of $\mathrm{T}$ cell activation and survival, which is required for the prevention of systemic autoimmune disease. 

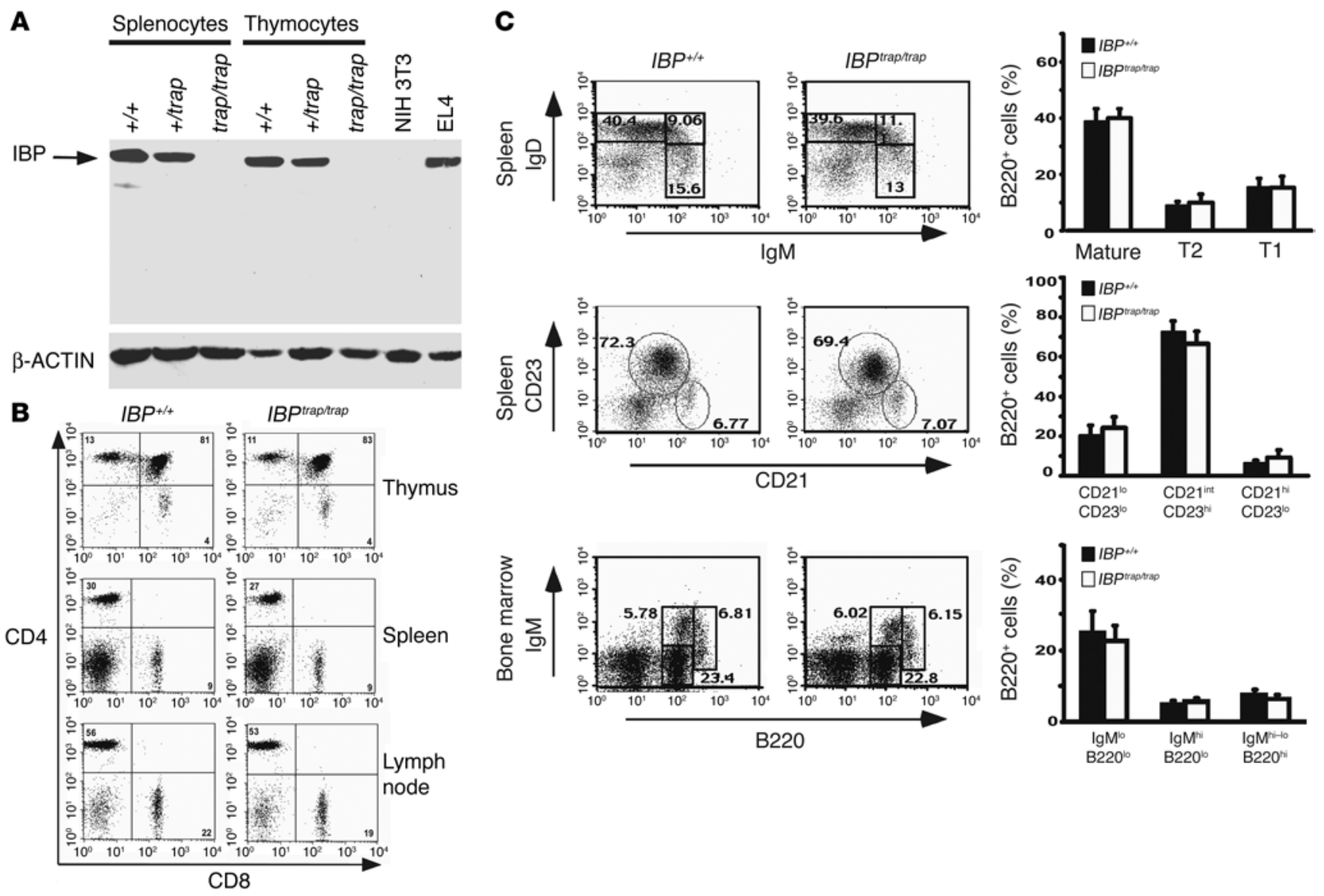

Figure 1

Lymphocyte development in IBPtrap/trap mice. (A) IBP protein expression in IBP $P^{+/+}$, IBP $P^{+/ t r a p}$, and IBPtrap/trap splenocytes and thymocytes. Total cell Iysates $(20 \mu \mathrm{g})$ were prepared from splenocytes and thymocytes and probed with an anti-IBP antibody reactive against the $C$ terminus of IBP (upper panel). Extracts from NIH 3T3 and EL4 cells were used as negative and positive controls, respectively. Reprobing with a $\beta$-actin antibody is shown as a loading control (lower panel). (B) Flow cytometric analysis of T lymphocyte populations from 6-week-old $I B P^{+/+}$and $I B P^{\text {trap/trap }}$ mice. Single-cell suspensions from thymus (upper panel), spleen (middle panel), and lymph nodes (lower panel) were stained with antibodies against CD4 and CD8. Percentages of positive cells within each quadrant are shown. (C) Flow cytometric analysis of $B$ lymphocyte populations from 6-week-old $I B P^{+/+}$and $I B P^{\text {trap/trap }}$ mice. Single-cell suspensions from splenic B220+ cells were stained with antibodies against lgM and IgD (top panel) and CD23 and CD21 (middle panel). Bone marrow cells (lower panel) were stained with antibodies against lgM and B220 and gated to show pro- and pre-, immature and mature B cells. Percentages of positive cells within each gate are shown.

\section{Results}

Lymphoid development is not affected by lack of IBP. To elucidate the physiologic role of IBP, IBP-deficient mice were generated utilizing a gene-trapping approach $(26,27)$. The gene-trapping vector was found to have integrated in the first intron of the IBP gene, just downstream of the first coding exon. This led to a complete loss of IBP expression as demonstrated by Western blotting with a carboxyterminal-specific antibody (Figure 1A) (20). IBPtrap/trap mice were born at the expected Mendelian frequency and were viable and fertile. An analysis of the cellularity and surface phenotypic markers of the lymphoid organs in 6-week-old mutant and control mice revealed no differences in size or lymphoid development (Table 1 and Figure 1, B and C).

Spontaneous development of a lupus-like syndrome in aging IBP-deficient female mice. Although young IBPtrap/trap mice appeared phenotypically normal, beginning at 5 months of age, approximately $60 \%$ of the females, but none of the control animals, started developing large nodal masses in the neck area. Dissection of the affected mice revealed multiple enlarged lymph nodes (often 10 times larger than WT controls) as well as splenomegaly (Figure 2A and Table 1). Serologic analysis demonstrated that aging (>5 months old) IBPtrap/trap female mice displayed markedly elevated serum IgG levels (Figure 2B). Although elevations in both IgG1 and IgG2a levels were noted, in most animals, IgG1 levels were increased to a greater extent than IgG2a levels (data not shown). The great majority of aging IBPtrap/trap female mice also had high titers of antinuclear antibodies (ANAs) (Figure 2C) as well as anti-double-stranded DNA (dsDNA) (Figure 2D) and anti-Smith (anti-Sm) antibodies (data not shown). These serologic findings were present even before IBPtrap/trap female mice developed any visible lymphadenopathy. Aging IBPtrap/trap female mice were also found to develop proteinuria and glomerulonephritis, which were associated with the deposition of IgG and C3 (Figure 2E). Although IBPtrap/trap males also exhibited hypergammaglobulinemia when compared with WT male mice, the increase in IgG was much less severe than that observed in the female IBPtrap/trap mice (Figure 2B), 
Table 1

Hematopoietic cellularity in IBPtrap/trap mice

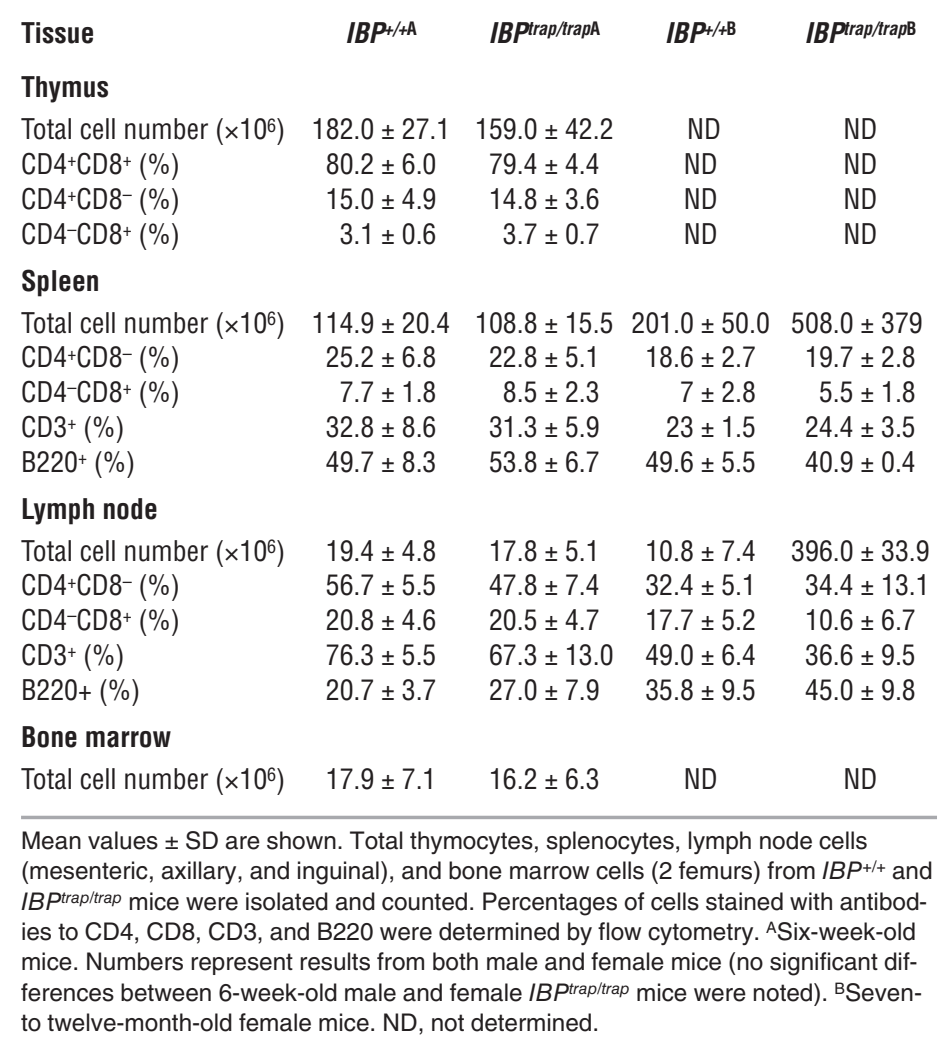

ited by the IBPtrap/trap female mice is therefore characterized by a striking accumulation of effector/memory $\mathrm{T}$ cells and of terminally differentiated B cells.

IBP-deficient $T$ cells are resistant to death. To elucidate the mechanisms responsible for the development of autoimmunity in IBPtrap/trap mice, a systematic evaluation of young ( 6 weeks old) IBPtrap/trap mice was carried out. To determine the effect of IBP deficiency on T cell proliferation, purified $T$ cells were stimulated with anti-CD3 and anti-CD28 antibodies, and DNA synthesis was measured by assessing the incorporation of $\left[{ }^{3} \mathrm{H}\right]$ thymidine after 3 days. As shown in Figure 4A, the proliferative responses of IBPtrap/trap T cells to TCR stimulation were modestly impaired. The IBPtrap/trap T cells, however, proliferated normally when cultured with PMA and ionomycin, indicating that IBP is required for proximal TCR signaling events necessary to achieve optimal proliferation.

The accumulation of effector/memory $\mathrm{T}$ cells in aging IBPtrap/trap mice, which occurred despite a decrease in the proliferative responses of these cells, suggested that lack of IBP might have an impact on the survival of T cells. To explore this possibility, we isolated naive $\mathrm{T}$ cells from WT and IBP-deficient mice, stimulated them for 3 days in vitro, and then reexposed them to increasing amounts of anti-CD3 for 24 hours. Apoptosis was then measured by staining the cells with propidium iodide (Figure 4B). The ability of IBPtrap/trap $\mathrm{T}$ cells to undergo apoptosis upon anti-CD3 restimulation was clearly diminished. To determine whether the resistance to apoptosis observed in the absence of IBP might lead to defective $\mathrm{T}$ cell homeostasis in vivo, we treated WT and IBPtrap/trap mice with the superantigen staphylococ-

and only a small percentage of IBPtrap/trap male mice developed autoantibodies (Figure 2D). Consistent with these findings, only approximately $10 \%$ of male mutant mice developed visible lymphadenopathy, and this has occurred at a much later age (approximately 15 months). Aging IBPtrap/trap female mice thus develop a syndrome that shares many similarities with human SLE.

To better characterize the lymphoproliferative disorder exhibited by the aging IBPtrap/trap mice, the spleen and lymph nodes of these mice were analyzed by FACS. A striking accumulation of $\mathrm{CD}^{+} \mathrm{T}$ cells displaying an effector/memory phenotype was observed in these mice (Figure 3A). No increase in $\mathrm{B} 220^{+} \mathrm{CD}^{+}$cells was noted (data not shown). Remarkably, although both spleen and lymph nodes of these animals contained B220 ${ }^{+}$cells, most of these cells did not express IgM and IgD (Figure 3B). A further analysis of the $\mathrm{B}$ cell populations in the IBPtrap/trap mice demonstrated a marked increase in the $\mathrm{B} 220^{+} \mathrm{PNA}^{\text {hi }}$ population (data not shown) and in the $\mathrm{B} 220^{\text {int }}$ syndecan- $1^{+}$plasma cell population but no increase in B-1 cells (Figure 3C and data not shown). Interestingly, FACS analysis of the bone marrow of these animals revealed a marked depletion of all B cell subsets and no significant accumulation of plasma cells (Figure 3C). A histological examination of the spleens and lymph nodes of the diseased IBPtrap/trap female mice demonstrated the presence of hyperplastic germinal centers with diffusely infiltrating plasma cells as demonstrated by staining with peanut agglutinin (PNA) and syndecan-1 (Figure 3D). Furthermore, while in WT mice, only rare IgG1 ${ }^{+} \mathrm{B}$ cells could be identified in the spleen, the mutant mice displayed a markedly increased number of IgG1 ${ }^{+} \mathrm{B}$ cells (Figure $\left.3 \mathrm{E}\right)$. The lymphoproliferative disorder exhib- cal enterotoxin B (SEB). Normally, SEB injection leads to an initial expansion of $\mathrm{V} \beta 8^{+} \mathrm{T}$ cells followed by their deletion. After injec-

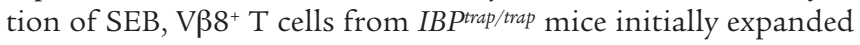
to almost the same degree as those from WT mice. Elimination of IBPtrap/trap $V \beta 8^{+} \mathrm{T}$ cells, however, was much less efficient than that of $\mathrm{V} \beta 8^{+} \mathrm{T}$ cells derived from WT mice (Figure $4 \mathrm{C}$ ). As expected, no changes in the percentages of $\mathrm{V} \beta 6^{+} \mathrm{T}$ cells, which do not respond to SEB, were observed in both WT and mutant mice (Figure 4C). IBP is thus necessary for the effective elimination of activated $T$ cells.

Two major pathways have been implicated in the control of the death of activated T cells: engagement of death receptors, especially the Fas receptor, and activation of an intrinsic pathway that involves the mitochondria (28). To investigate the mechanism(s) responsible for the decreased ability of the IBP-deficient $T$ cells to undergo apoptosis, we thus assessed the effects of lack of IBP on each of these 2 major pathways. IBP deficiency did not alter the expression of Fas or FasL on T cells, and engagement of the Fas receptor by an anti-Fas antibody induced similar levels of apoptosis in WT and IBP-deficient T cells (data not shown). However, upon CD3 restimulation, WT T cells exhibited a significantly greater loss of mitochondrial membrane potential than IBPtrap/trap $\mathrm{T}$ cells (Figure 4D). Taken together, these results suggest that the accumulation of effector/memory T cells observed in the IBPtrap/trap mice results from a defective ability of these $T$ cells to undergo apoptosis via a cell autonomous pathway.

Lack of IBP leads to selective impairments in $\mathrm{CD}^{+} \mathrm{T}$ cell effector function. In addition to defects in survival, $T$ cells from SLE patients also exhibit functional impairments, in particular a diminished abil- 

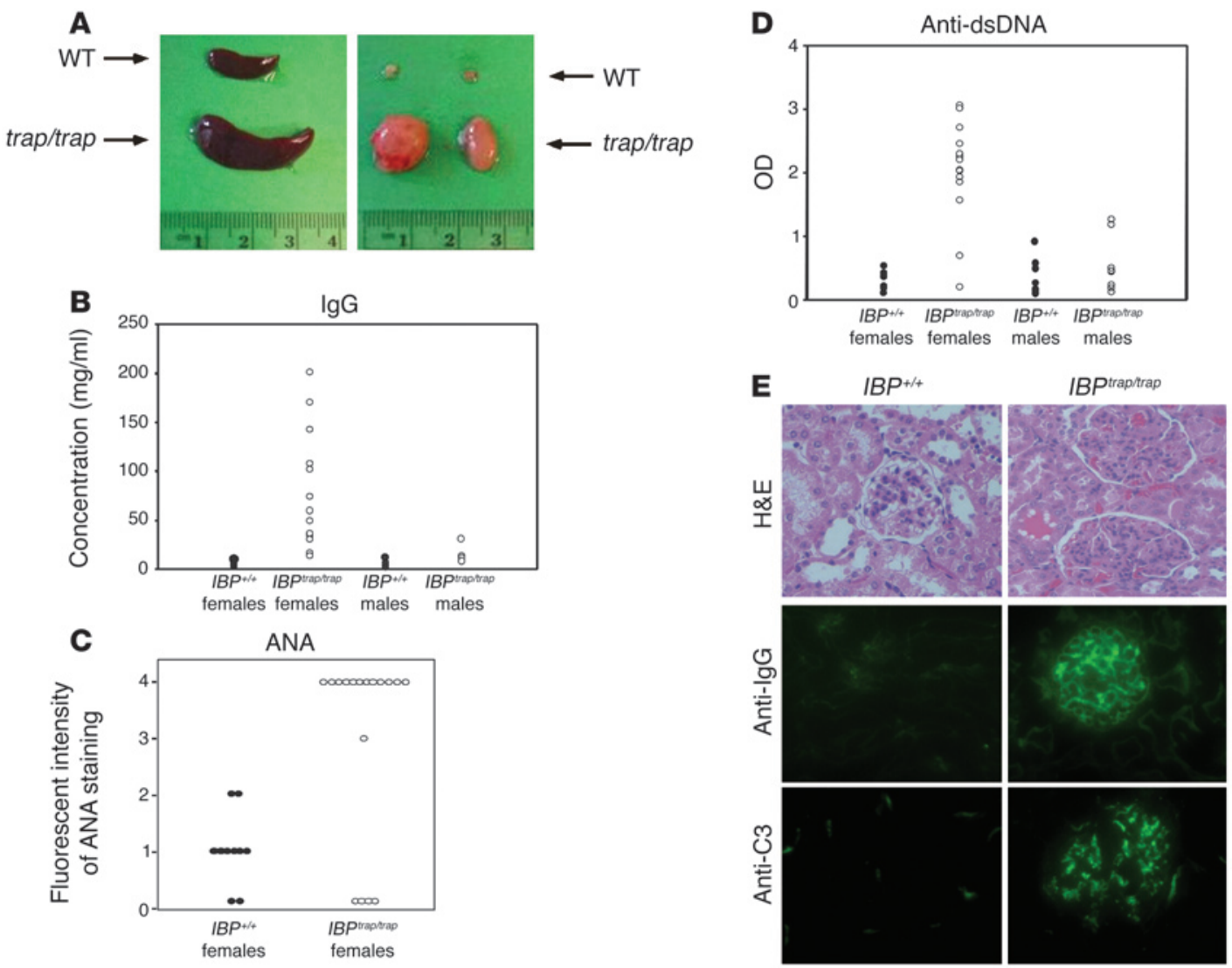

\section{Figure 2}

Aging IBPtrap/trap female mice develop a lupus-like syndrome. (A) Spleens (left panel) and lymph nodes (right panel) of 7-month-old IBP+/+ and IBPtrap/trap female mice are shown. (B) Total serum IgG levels in older (5-12 months old) IBP+/+ (filled circles) or IBPtrap/trap (open circles) mice were determined by ELISA. Each symbol represents 1 mouse of $I B P^{+/+}$females $(n=7)$, IBPtrap/trap females $(n=13)$, IBP+/+ males $(n=6)$, and IBPtrap/trap males $(n=6)$. (C) ANA titers were determined from IBP+/+ (filled circles) or IBPtrap/trap (open circles) female mice (5-12 months old) by measuring the intensity of fluorescent staining of ANAs on a scale ranging from 0 to 4 , with 4 being the highest intensity. Data shown represent $I B P^{+/+}$female $(n=8)$ and IBPtrap/trap female mice $(n=13)$. (D) Anti-dsDNA antibody titers in the serum of older $(5-12$ months old $) I B P^{+/+}($filled circles) or IBPtrap/trap (open circles) mice were determined by ELISA. Each symbol represents 1 mouse of $I B P^{+/+}$females $(n=7)$, IBP trap/trap females $(n=16), I B P^{+/+}$males $(n=4)$, and IBPtrap/trap males $(n=6)$. (E) Histological analysis of H\&E-stained sections from the kidney of 7-month-old

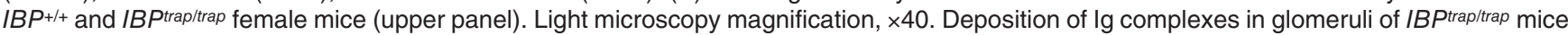
as detected by immunofluorescence with anti-IgG (middle panel) and anti-C3 (bottom panel) staining. Results are representative of 5 mice.

ity to produce cytokines such as IL-2 (8). We thus proceeded to directly examine whether lack of IBP affects the effector function of peripheral T cells. When compared with WT T cells, IBPtrap/trap T cells exhibited a decreased ability to produce IL-2 (Figure 5A) and IFN- $\gamma$ (Figure 5B) upon TCR stimulation. In contrast, IL-4 synthesis was comparable to that of control T cells (Figure 5B). Bypassing the early steps in TCR signaling by stimulating the IBPtrap/trap T cells with PMA and ionomycin could rescue the defects in IL-2 and IFN- $\gamma$ production displayed by these $\mathrm{T}$ cells (Figure 5, A and B). The defects in cytokine production were also observed when purified naive $\mathrm{CD}^{+} \mathrm{T}$ cells were assayed (data not shown). To further investigate the defects in the production of Th1-type cytokines, naive $\mathrm{CD}^{+}{ }^{+} \mathrm{T}$ cells from WT and IBP-deficient mice were primed either in the absence of cytokines or in the presence of cytokines that would skew them toward a Th1 or a Th2 differentiation pathway. After 7 days, cells cultured under each of the 3 conditions were restimulated with anti-CD3, and cytokine production was assessed by ELISA (Figure 5C). In agreement with our earlier observations, IBPtrap/trap $\mathrm{T}$ cells cultured under unskewed conditions exhibited defective IFN- $\gamma$ production but maintained a normal ability to synthesize IL-4. Interestingly, priming of IBPtrap/trap T cells with IL-12 rescued the defective production of IFN- $\gamma$ by IBPtrap/trap $\mathrm{T}$ cells while exposure of IBP trap/trap $^{\mathrm{T}}$ cells to Th2 skewing conditions again did not reveal any defects in IL-4 production. These results thus suggest that optimal production of IL- 2 and IFN- $\gamma$ upon TCR engagement requires the presence of IBP. Addition of IL-12 during the primary stimulation, however, can render the requirement for IBP in the production of Th1-type cytokines less stringent.

IBP-deficient mice display enhanced T cell-dependent humoral responses in vivo. Given the abnormal antibody responses exhibited by the aging IBPtrap/trap mice, the effect of IBP deficiency on the B cell compartment was also investigated. Purified B cells from WT and mutant mice displayed similar proliferative responses to a variety of mitogenic stimuli (Figure 6A). Furthermore, when purified WT and IBP-deficient $B$ cells were differentiated in vitro with LPS and IL-4 or anti-CD40 and IL-4, no difference in the number of plas- 
A
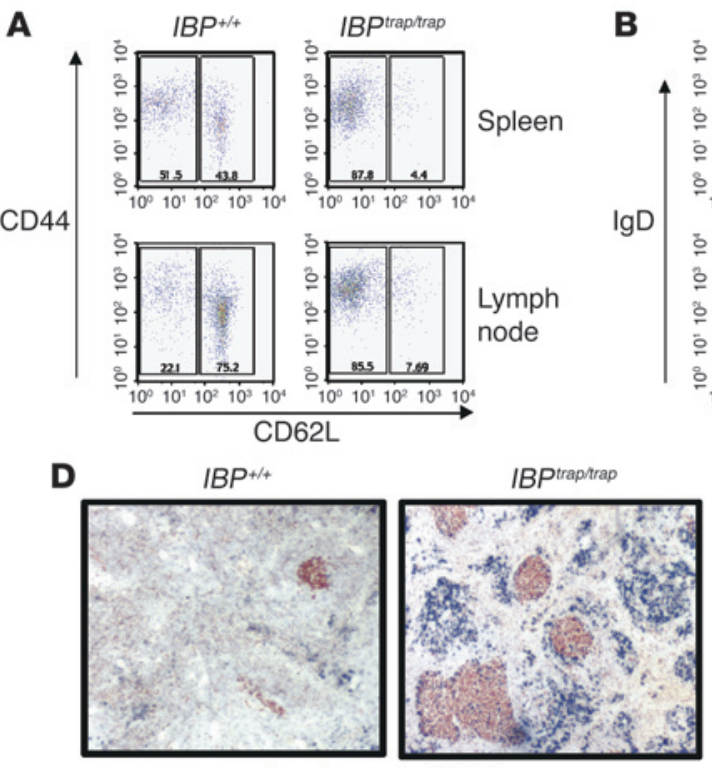

Syndecan-1: BLUE PNA: RED

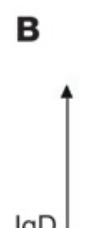

$\lg \mathrm{D}$

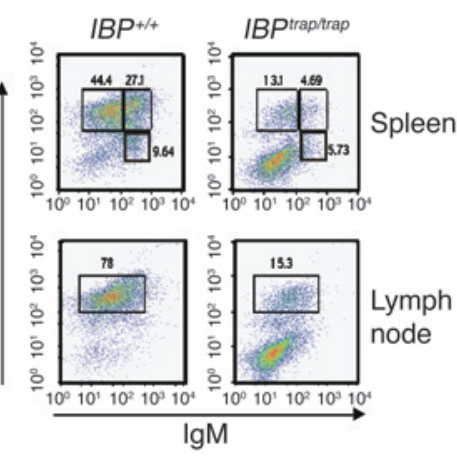

E

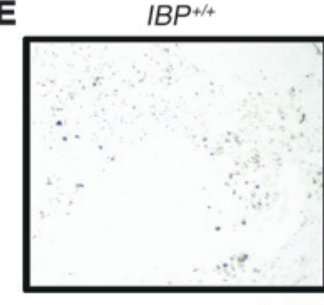

C
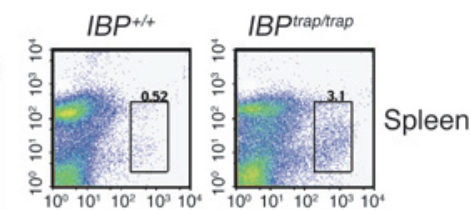

B220

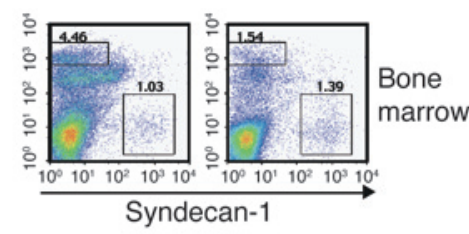

IBPtraptrap

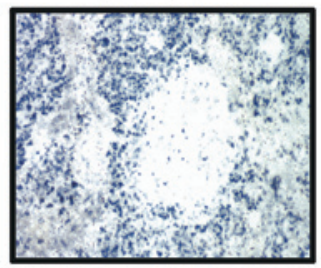

IgG1: BLUE

Figure 3

Accumulation of effector/memory-like T cells and terminally differentiated B cells in aging IBPtrap/trap mice. (A) Increased effector/memory T cells in aging IBPtrap/trap female mice. Cell suspensions from spleen (top panels), and lymph nodes (bottom panels) from older IBP+/+ and IBPtrap/trap mice were stained with antibodies against CD4, CD44, and CD62L to evaluate the presence of naive (CD44/。CD62Li) and effector/memory $\left(C D 44^{\text {hiCD62 }} \mathrm{L}^{10}\right) \mathrm{T}$ cells. Dot plots represent gated CD4+ populations. Percentages of positive cells within each gate are shown. Results are representative of 5 different mice. (B) Alterations of B cell populations in aging IBPtrap/trap female mice. Single-cell suspensions from spleen (top

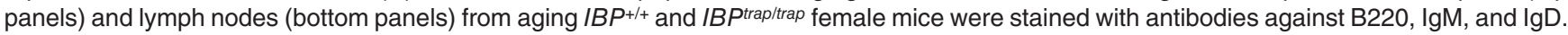
Cell staining was analyzed by FACS. Dot plots represent gated B220+ populations. Percentages of positive cells within each gate are shown. (C) Increased plasma cells in spleens of aging IBPtrap/trap female mice. Single-cell suspensions from spleen (top panels) and bone marrow (bottom panels) from $I B P^{+/+}$and older IBPtrap/trap female mice were stained with antibodies against B220 and syndecan-1. Cell staining was analyzed by FACS. Percentages of syndecan-1-positive cells within each gate are shown. (D) Syndecan-1 and PNA staining of spleens of aging IBPtrap/trap female mice. Anti-syndecan-1 (blue) and anti-PNA (red) staining were performed on spleens from IBP +/+ (left panel) and IBPtrap/trap (right panel) mice. Light microscopy magnification, $\times 10$. (E) Accumulation of IgG1+ cells in spleens of aging IBPtrap/trap female mice. Anti-IgG1 (blue) staining was performed on spleens from IBP ${ }^{+/+}$(left panel) and IBPtrap/trap (right panel) mice. Light microscopy magnification, $\times 10$.

ma cells or in the production of IgG1 or IgE was detected (data not shown). An examination of the serum Ig levels of WT and IBPdeficient mice, however, revealed that IBPtrap/trap mice displayed statistically significant increases in the basal serum levels of IgG1 and $\operatorname{IgE}$ (Figure 6B). Furthermore, while immunization of IBPtrap/trap mice with the $\mathrm{T}$ cell-independent antigen 4-hydroxy-3nitrophenylacetyl-Ficoll (NP-Ficoll) exerted only a minimal effect on NP-specific antibody responses, IBPtrap/trap mice immunized with the $\mathrm{T}$ cell-dependent antigen NP-keyhole limpet hemocyanin (NP-KLH) exhibited a marked increase in the production of IgE (Figure 6C and data not shown). Thus, lack of IBP in vivo leads to marked increases in the production of Ig isotypes normally associated with Th2 responses.

Lack of IBP leads to decreased ERK1/2 activation. The rapid activation of IBP in response to TCR stimulation coupled with the finding that stimuli that bypass the early steps in TCR signaling could rescue the defects exhibited by the IBPtrap/trap T cells led us to explore the possibility that the defective $\mathrm{T}$ cell responses observed in the IBPtrap/trap mice might be linked to specific abnormalities in TCR signaling pathways. An examination of the activation of Lck, as assessed by the phosphorylation of Y394 (29), revealed that this step was not affected by the lack of IBP (Figure 7A). Similarly, the TCR-mediated activation of ZAP-70, as reflected by the phosphorylation of tyrosine 319 , also proceeded normally in IBPtrap/trap $\mathrm{T}$ cells (Figure 7A). Furthermore, IBPtrap/trap $\mathrm{T}$ cells were able to achieve cytosolic $\mathrm{Ca}^{2+}$ levels comparable to those of WT T cells although these cells consistently displayed a slightly longer lag time to the onset of $\mathrm{Ca}^{2+}$ signal (Figure 7B). IBP, therefore, is not required for the initial wave of TCR-mediated tyrosine kinase activity or for TCR-induced $\mathrm{Ca}^{2+}$ signaling.

TCR engagement is followed by the activation of additional downstream effector kinases, notably ERK1/2, members of the MAPK family (30). Activation of ERK1/2 subsequently mediates the induction of immediate early genes such as c-Fos, a member of the activating protein-1 (AP-1) family of transcription factors, which play a key role in cytokine gene expression (31). Upon TCR stimulation, ERK1/ 2 activation was markedly reduced in IBPtrap/trap $\mathrm{T}$ cells, although these cells were able to activate ERK1/2 to levels similar to WT cells when stimulated with PMA (Figure 7C). Consistent with these findings, IBPtrap/trap $\mathrm{T}$ cells also exhibited impairments in the upregulation of c-Fos (Figure 7D). No defects in JNK1/2 or p38 activation were instead noted (Supplemental Figure 1; available online with this article; doi:10.1172/JCI24096DS1).

Immunological synapse formation and TCR-induced actin polymerization are defective in IBP-deficient T cells. Optimal T cell function is critically dependent on the proper assembly of the immunological synapse and cytoskeletal reorganization (10). Given that IBP can translocate to 
A
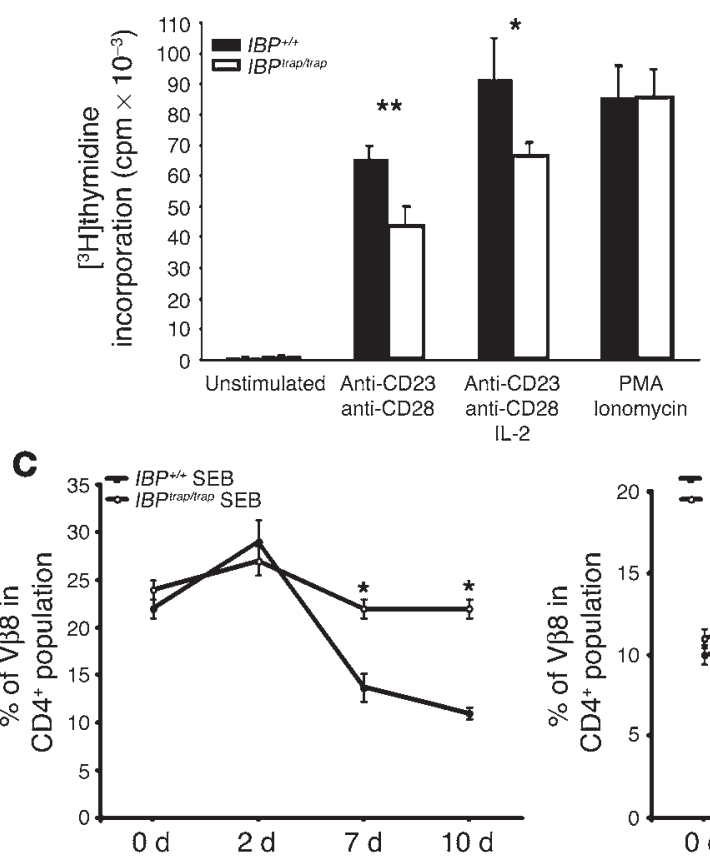

B

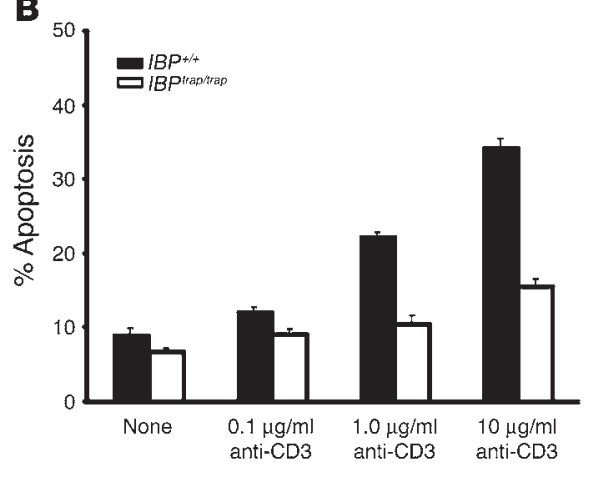

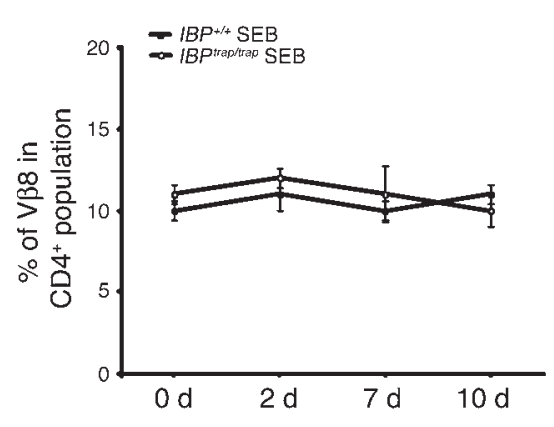

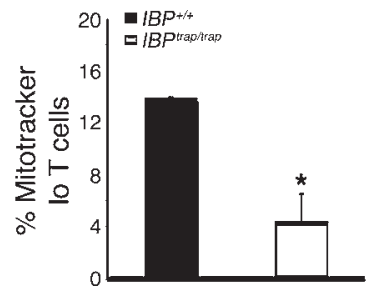

Figure 4

IBPtrap/trap T cells are resistant to apoptosis. (A) Proliferation of T cells from WT and IBP mutant mice. Cells were stimulated with plate-bound anti-CD3ع (2C11) $(1 \mu \mathrm{g} / \mathrm{ml})$ and soluble anti-CD28 $(1 \mu \mathrm{g} / \mathrm{ml})$ antibodies or with PMA $(50 \mathrm{ng} / \mathrm{ml})$ plus ionomycin $(1 \mu \mathrm{M})$ for $48 \mathrm{hours}$. The culture was then pulsed with $\left[{ }^{3} \mathrm{H}\right]$ thymidine for 18 hours. This experiment is representative of 5 independent experiments. The data were analyzed using 2-tailed Student's $t$ test. A statistical probability of $P<0.05$ was considered significant. ${ }^{*} P<0.05$; ${ }^{* *} P<0.005$ (IBP traptrap versus WT). (B) Apoptosis of $I B P^{+/+}$and IBPtrap/trap $\mathrm{T}$ cells upon CD3 restimulation. Purified naive $\mathrm{CD} 4^{+} \mathrm{T}$ cells from IBP ${ }^{+/+}$(black bars) or IBP trap/trap (white bars) mice were stimulated for 3 days and then harvested. The cells were then restimulated with either IL-2 alone or IL-2 with anti-CD3 mAbs at the indicated doses for 24 hours. Cells were then stained with propidium iodide, and the percentage of apoptotic cells was determined by quantification of the sub- $G_{0}$ population by FACS. Each assay was conducted in duplicate. The experiment is representative of 3 separate experiments. (C) SEB-specific deletion of T cells in IBPtrap/trap mice. IBP $P^{+/+}(n=4)$ (filled circles) and IBPtrap/trap $(n=4)$ (open circles) mice were injected i.p. with SEB on day 0. Peripheral blood cells were stained with antibodies against V $\beta 8$ and CD4 (left panel) or V $\beta 6$ and CD4 (right panel) and analyzed by FACS at the indicated time points. Results are expressed as a mean \pm SD. Statistical differences were determined using 2-tailed Student's $t$ test. (D) Loss of mitochondrial potential. Purified naive CD4 ${ }^{+} \mathrm{T}$ cells from IBP+/+ (black bars) or IBPtrap/trap (white bars) mice were stimulated for 3 days and then harvested. The cells were then restimulated with either IL-2 alone or IL-2 with anti-CD3 mAbs at $10 \mu \mathrm{g} / \mathrm{ml}$ for 24 hours. Cells were then stained with Mitotracker Deep Red 633 to assess loss of mitochondrial potential. The percentage of cells that displayed a decrease in intensity of staining (Mitotracker lo T cells) is indicated. The experiment is representative of 3 separate experiments. Results are expressed as mean \pm SD. Statistical differences were determined using 2-tailed Student's $t$ test.

the immunological synapse and can activate Rho GTPases, the effect of IBP deficiency on the formation of the immunological synapse was examined. Purified $\mathrm{CD}^{+} \mathrm{T}$ cells from WT and IBPtrap/trap mice were incubated with APCs in the presence or absence of superantigen (staphylococcal enterotoxin E [SEE]) (Figure 8, A and B). Conjugate formation was then assessed by determining the recruitment of a phosphorylated form of ZAP-70 to the T cell-APC interface. Although the initial recruitment of phosphorylated ZAP-70 to the synapse was similar in WT and IBP-deficient T cells, IBPtrap/trap T cells displayed a decreased accumulation of phosphorylated ZAP-70 at the $\mathrm{T}$ cell-APC interface at later time points (Figure 8, A and B). A similar pattern was observed when the recruitment of a phosphorylated form of linker for activation of T cells (LAT) was examined (Figure 8A). These results thus indicate that, in the absence of IBP, assembly of the immunological synapse cannot be properly maintained.

To further explore the role of IBP in T cell cytoskeletal reorganization, we employed a retroviral transduction system to reintroduce either WT IBP (IBP-retroviral [IBP-RV]) or an IBP mutant lacking the Dbl-like domain (IBP $\Delta 313-631-R V)$ necessary for Rho GTPase activation into IBPtrap/trap primary $T$ cells and assessed their effect on TCR-mediated actin polymerization by flow cytometry (Figure 8C). In the absence of stimulation, WT and mutant T cells contained similar amounts of F-actin. Upon TCR stimulation, however, WT T cells demonstrated an increase in F-actin content while IBPtrap/trap T cells failed to do so. Reconstitution of WT IBP expression into IBPtrap/trap $\mathrm{T}$ cells was able to restore actin polymerization to levels comparable to those obtained by WT T cells. In contrast, IBPtrap/trap $\mathrm{T}$ cells infected with IBPA313-631-RV were still incapable of polymerizing actin in response to TCR stimulation. Reconstitution with a retroviral construct expressing a constitutively active form of Rac2 (Rac2G12V) also partially rescued the actin polymerization defects exhibited by the IBPtrap/trap $\mathrm{T}$ cells, supporting the notion that these cells indeed display defective activation of Rho GTPases. Taken together, these data suggest that the ability of IBP to activate Rho GTPases is required for TCRmediated cytoskeletal reorganization. 

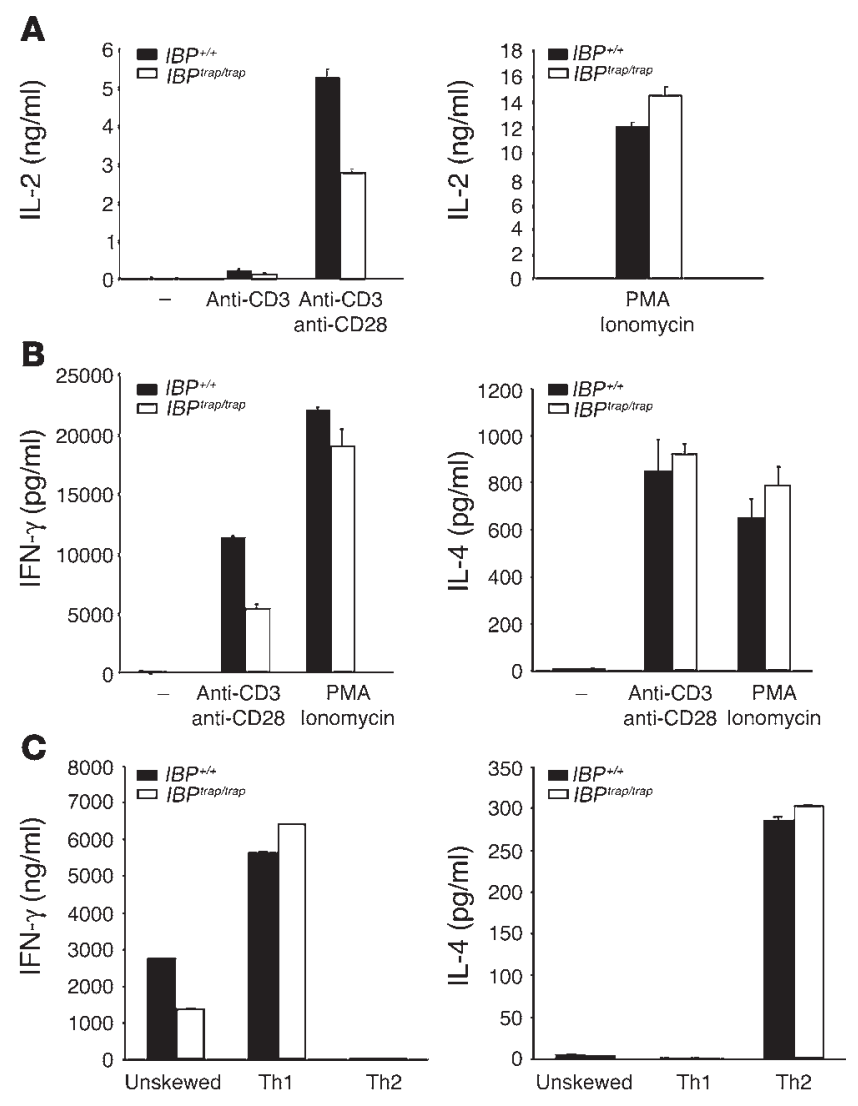

\section{Discussion}

In the present study, we demonstrate that lack of IBP leads to the spontaneous development of a lupus-like syndrome characterized by the accumulation of effector/memory T cells and of $\mathrm{IgG}^{+} \mathrm{B}$ cells, profound hypergammaglobulinemia, autoantibody production, and glomerulonephritis. Consistent with these findings, in vitro and in vivo studies indicate that the absence of IBP profoundly affects the survival of antigen-experienced T cells. Lack of IBP also leads to selective impairments in $\mathrm{T}$ cell effector function, which are associated with diminished ERK1/2 activation and impaired cytoskeletal reorganization. Reintroduction of full-length IBP or of constitutively active Rac2, but not of an IBP mutant lacking

\section{Figure 6}

Enhanced T cell-dependent humoral responses in IBPtrap/trap mice. (A) Proliferation of $B$ cells. Cells were stimulated with soluble anti-CD40 $(5 \mu \mathrm{g} / \mathrm{ml})$, LPS $(10 \mu \mathrm{g} / \mathrm{ml})$, or anti-lgM $(10 \mu \mathrm{g} / \mathrm{ml})$ with or without IL-4 $(20 \mathrm{ng} / \mathrm{ml})$ for 48 hours. The culture was then pulsed with $\left[{ }^{3} \mathrm{H}\right]$ thymidine for 18 hours. (B) Basal Ig levels in IBPtrap/trap mice. Serum Ig levels from nonimmunized 6-week-old $I B P^{+/+}$(filled circles) and IBPtrap/trap (open circles) mice were determined by isotype-specific ELISA. Each symbol represents 1 mouse. Horizontal bars are drawn through the mean value of each group. ${ }^{*} P<0.005$ (IBPtrap/trap versus WT). (C) $\mathrm{T}$ cell-dependent immunizations. IBP+/+ (filled circles) and IBPtrap/trap (open circles) mice were immunized with NP-KLH. Relative amounts of NP-specific $\lg M, \lg G_{1}, \lg _{2 a}$, and $\lg _{3}$ antibodies and total $\lg E$ levels at the indicated times after primary immunization were determined by ELISA. Each symbol represents 1 mouse. Horizontal bars are drawn through the mean value of each group. The data were analyzed using Student's $t$ test. A statistical probability of $P<0.05$ was considered significant. ${ }^{*} P<0.05 ;{ }^{* *} P<0.005$ (IBPtrap/trap versus WT).

\section{Figure 5}

IBP regulates $T$ cell effector function. (A) IL-2 production by WT and IBP mutant T cells. Purified CD4+ $\mathrm{T}$ cells were stimulated with immobilized anti-CD3 $\varepsilon$ antibody $(1 \mathrm{\mu g} / \mathrm{ml})$ alone or together with soluble anti-CD28 antibody $(1 \mu \mathrm{g} / \mathrm{ml})$ (left panel) or with PMA $(50 \mathrm{ng} / \mathrm{ml})$ and ionomycin $(1 \mu \mathrm{M})$ (right panel) for 24 hours. IL-2 levels in culture supernatants were determined by ELISA. The experiment is representative of 5 independent experiments. (B) IFN- $\gamma$ and IL- 4 production by WT and IBP mutant T cells. Cells were stimulated as in A for 48 hours. Production of IFN- $\gamma$ (left panel) and IL-4 (right panel) was measured by ELISA. The experiment is representative of 5 independent experi-

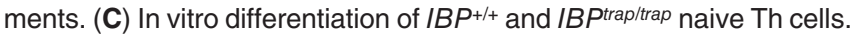
Naive CD4+ $T$ cells were isolated from WT and IBPtrap/trap mice and differentiated in vitro under unskewed, Th1, or Th2 conditions. After 7 days, unskewed, Th1, and Th2 cells from $I B P^{+/+}$and $I B P^{\text {trap/trap }}$ mice were stimulated with anti-CD3 antibody for 24 hours and supernatants analyzed for cytokine production. IFN- $\gamma$ (left panel) and IL-4 (right panel) production was measured by ELISA. The experiment is representative of 5 independent experiments.

its Dbl-like domain, rescues the defective cytoskeletal responses of IBP-deficient T cells. Collectively, these data thus support the notion that IBP is a novel type of Rho GTPase activator that is required for optimal $\mathrm{T}$ cell effector function, homeostasis, and the prevention of systemic autoimmune disease.

Similarly to human SLE, development of the lupus-like syndrome in IBP-deficient mice displays a striking sex preference, with IBPtrap/trap female mice being affected to a much greater extent than IBPtrap/trap male mice. Furthermore, like lupus $\mathrm{T}$ cells, activated $\mathrm{T}$ cells from IBPtrap/trap mice exhibit a marked resistance to undergoing apoptosis (32). In addition, the defective IL-2 production, which is coupled to

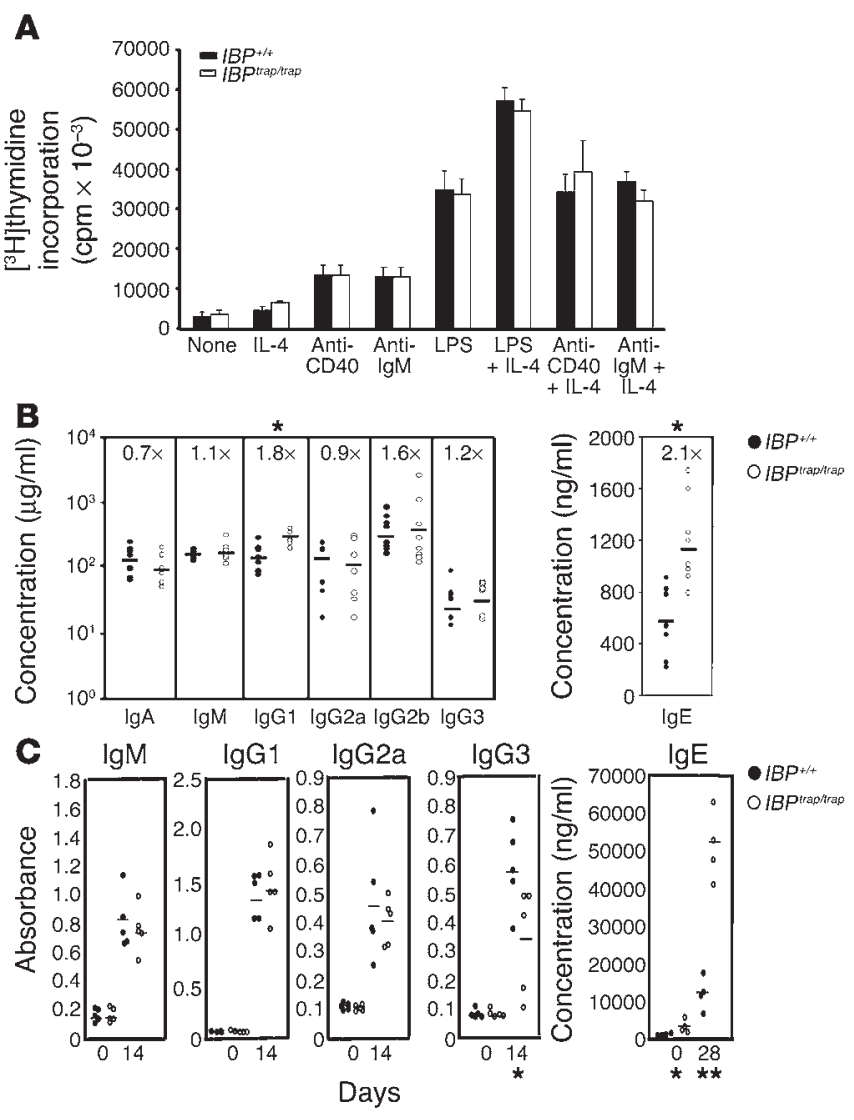


A

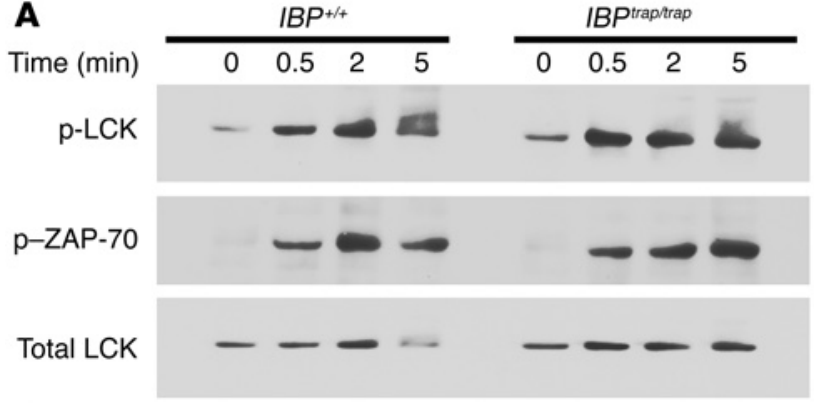

B

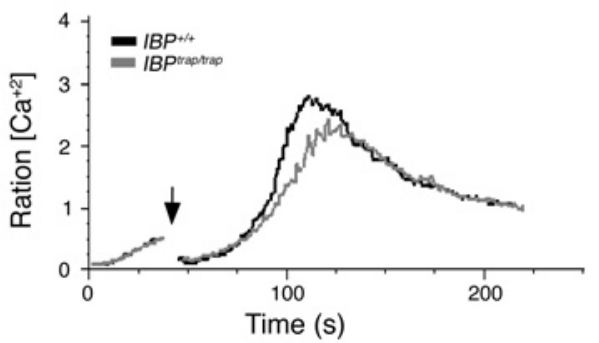

C

\begin{tabular}{lllllllllllll}
\cline { 2 - 5 } & 0 & 2 & 5 & 10 & 30 & $\mathrm{P} / 1$ & 0 & 2 & 5 & 10 & 30 & $\mathrm{P} / \mathrm{l}$
\end{tabular}

p-ERK1/2

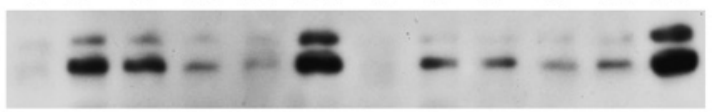

ERK1/2

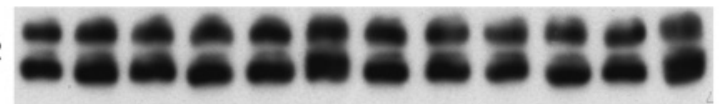

D
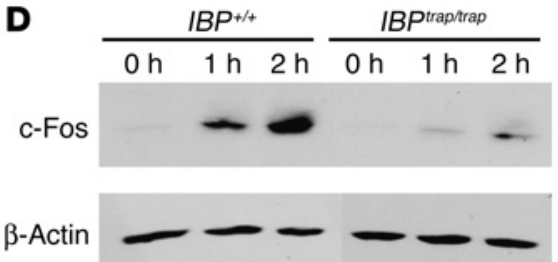

Figure 7

Defective ERK1/2 activation in IBPtrap/trap T cells. (A) Lck and ZAP-70 activation in IBPtrap/trap T cells was detected by Western blotting utilizing antibodies specific for Tyr 394 phosphorylated Lck (upper panel) and Tyr 319 phosphorylated ZAP-70 (middle panel). Reprobing with an antibody against total Lck is shown as a loading control (lower panel). (B) TCR-mediated calcium mobilization in IBP $P^{+/+}$and $I B P^{\text {trap/trap }} \mathrm{T}$ cells. Lymph node cells were loaded with Fura-red and Fluo-4 and surface stained with APC-labeled anti-CD4 antibody. Cells were then precoated with $5 \mu \mathrm{g}$ antiCD3 $(2 \mathrm{C} 11)$ antibody and cross-linked with goat anti-hamster Ig. Histogram data are presented as a median ratio of calcium mobilization gated on $\mathrm{CD}^{+}$cells as measured by FACS. The black line represents $I B P^{+/+} \mathrm{T}$ cells, and the gray line represents $I B P$ trap/trap $\mathrm{T}$ cells. Arrow indicates the addition of cross-linking antibody. (C) ERK activation in IBP+/+ and IBPtrap/trap $\mathrm{T}$ cells. Cells were stimulated with anti-CD3 $\varepsilon$ antibody for the indicated times or PMA $(50 \mathrm{ng} / \mathrm{ml})$ for 2 minutes as a control. Whole-cell lysates were prepared and active ERK $1 / 2$ detected by Western blotting using an anti-phosphorylated ERK antibody (upper panel). Total ERK1/2 levels are shown in the lower panel. (D) Induction of c-Fos in IBPtrap/trap

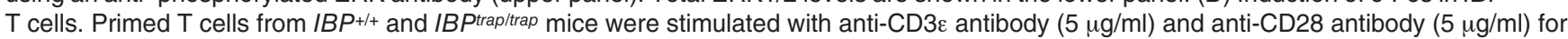
0,1 , or 2 hours. Lysates were prepared and levels of c-Fos detected by Western blotting using an anti-c-Fos antibody (upper panel). Reprobing with a $\beta$-actin antibody is shown as a loading control (lower panel).

decreased ERK1/2 activation, and impaired c-Fos induction are very reminiscent of the biochemical and functional defects that have previously been described in SLE patients (8). Preliminary results, furthermore, indicate that, similarly to what has been reported for SLE patients $(33,34)$, T cells from IBP-deficient mice express higher levels of CREM, a repressor known to downregulate IL-2 production and c-Fos induction (Q. Chen, unpublished observations). Impairments in IFN- $\gamma$ production in SLE patients have also been previously reported (35). Other abnormalities that have been observed in T cells from lupus patients were, however, not detected in IBPtrap/trap T cells. Indeed, while SLE T cells exhibit reduced Lck levels (36), expression of this kinase was unaffected by the absence of IBP. Furthermore, while IBPtrap/trap T cells exhibited significant impairments in actin polymerization and immunological synapse formation, anti-CD3-mediated capping and actin polymerization kinetics are accelerated in SLE patients (37). Given that the abnormal phenotype of the SLE T cells can be further amplified by exposure to SLE serum (38), however, some of the differences observed between the IBPtrap/trap $\mathrm{T}$ cells and the T cells from SLE patients may, in part, be secondary to the chronic exposure of the SLE T cells to a pathogenic microenvironment.

Elimination of antigen-experienced $\mathrm{T}$ cells is crucial for the maintenance of $\mathrm{T}$ cell homeostasis $(1,2)$, and genetic manipulations that alter the ability of $\mathrm{T}$ cells to be efficiently eliminated are commonly associated with the emergence of autoimmune pathophysiology (39). The marked defects in the ability of activated IBPtrap/trap T cells to undergo apoptosis are therefore likely to play a major role in the accumulation of effector/memory $\mathrm{T}$ cells and in the development of the lupus-like syndrome detected in these mice. Although IL- 2 and IFN- $\gamma$ are important for the control of T cell survival (40-42), the defective production of these cytokines by the IBPtrap/trap $\mathrm{T}$ cells was found not to underlie the aberrant apoptotic responses of these cells, since provision of exogenous IL-2 or IFN- $\gamma$ did not rescue the defects (Figure 4B and data not shown). Interestingly, an investigation of the 2 major pathways controlling the death of activated T cells (28) revealed that lack of IBP selectively affects the cell-intrinsic, or mitochondrial-mediated, pathway. Surprisingly, this defect was not due to changes in the expression of $\mathrm{Bcl}-2$ since IBPtrap/trap $\mathrm{T}$ cells did not display any increases in the expression of this antiapoptotic molecule (W. Yang, unpublished observations). Other members of this family in addition to $\mathrm{Bcl}-2$ have, however, been shown to participate in the control of the death of immune cells (43). Furthermore, many Bcl-2 family members can be regulated not only at the transcriptional level but also by additional mechanisms such as phosphorylation, proteolytic cleavage, and, interestingly, sequestration by cytoskeletal proteins (44). A systematic examination of the effects of IBP deficiency in the complex regulation of this family of proteins will thus be critical to fully elucidating its role in this fundamental process. 

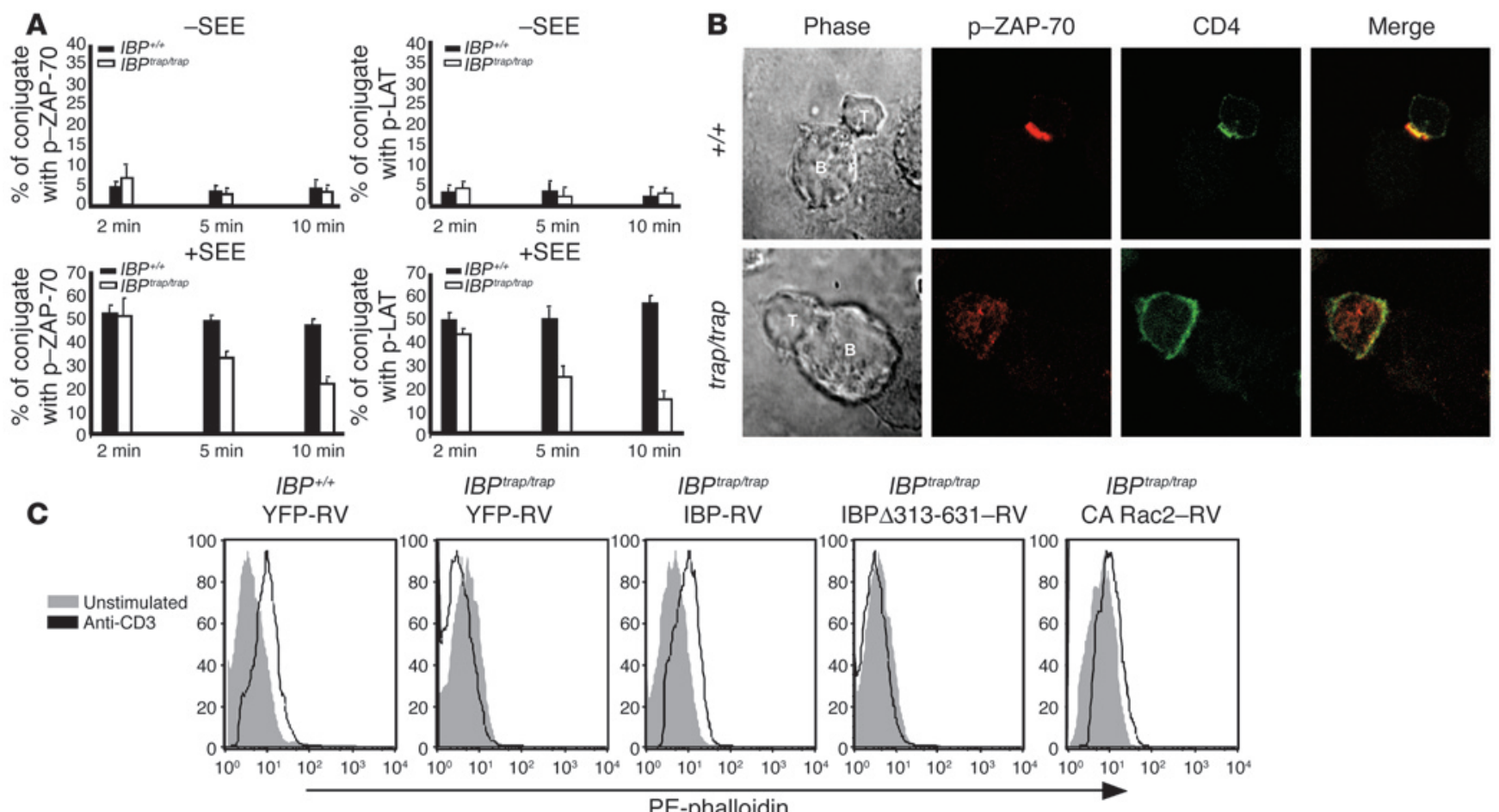

PE-phalloidin

\section{Figure 8}

IBPtrap/trap $T$ cells display impaired synapse formation and actin polymerization. (A) Formation of the immunological synapse in IBPtrap/trap $C D 4^{+} \mathrm{T}$ cells. CD4+ T cells were conjugated with A20 mouse B lymphoma cells loaded with or without $2 \mu \mathrm{g} / \mathrm{ml} \mathrm{SEE}$. After the indicated times of T and B cell contact, cells were stained with antibodies against either phosphorylated ZAP-70 or phosphorylated LAT and scored under a fluorescence microscope. Approximately 50 conjugates were counted per time point in at least 3 independent experiments. T and B cell conjugates without SEE (upper panels) and with SEE (lower panels) are shown. (B) Representative images for conjugates (phase), phosphorylated ZAP-70 (red) and CD4 (green) at 5 minutes in IBP+/+ and IBPtrap/trap $\mathrm{T}$ cells, respectively. (C) Actin polymerization in IBPtrap/trap $\mathrm{CD}^{+} \mathrm{T}$ cells reconstituted with WT or mutant IBP retroviral vectors. Naive CD4+ T cells were infected with control YFP-RV (empty vector) and WT IBP-expressing (IBP-RV), IBP- $\Delta 313-631-e x p r e s s i n g$ (IBP- $\Delta 313-631-R V)$, or constitutively active Rac2-expressing (CA Rac2-RV) retroviruses. Cells were harvested after 5 days and restimulated with anti-CD3 $\varepsilon$ antibodies followed by cross-linking with goat anti-hamster $\lg$ at $4^{\circ} \mathrm{C}$ (control) or $37^{\circ} \mathrm{C}$. Cells were then stained with biotin-labeled phalloidin followed by streptavidin-PE (PE-phalloidin) and actin polymerization measured by FACS. Data shown represent unstimulated cells (filled histogram) with overlay of stimulated cells (open histogram) after gating on YFP-positive cells.

TCR-mediated cytoskeletal remodeling is essential for the large-scale reorganization of receptors and signaling molecules that underlies the assembly of the immunological synapse. Furthermore, sustained synapse assembly is required for optimal IL-2 production and the full achievement of $\mathrm{T}$ cell effector potential (45). The defective TCR-mediated actin polymerization exhibited by IBPtrap/trap $\mathrm{T}$ cells and their failure to properly sustain the formation of the immunological synapse can thus partly explain the impaired $\mathrm{T}$ cell effector responses detected in the absence of IBP. Consistent with the notion that Rho GTPases play a key role in cytoskeletal reorganization and that IBP can activate these GTPases in a TCR-dependent manner, the defects in TCR-mediated actin polymerization detected in the absence of IBP are dependent on its ability to activate Rho GTPases as indicated by our retroviral transduction studies. Interestingly, $\mathrm{T}$ cells lacking Vav also display defects in cytoskeletal dynamics as well as alterations in ERK1/2 activation $(17,18)$, suggesting that the actions of both classes of Rho GTPase activators are required for these processes. Whether Vav and IBP cooperate in the control of a specific regulatory step or target different steps in the complex cascades controlling these processes, however, remains to be determined.
The biochemical and functional defects exhibited by the IBPtrap/trap $\mathrm{T}$ cells are likely to be molecularly linked, given that ERK1/2 can control the induction of c-Fos and that, in turn, members of the AP-1 family of transcription factors can regulate IL-2 gene transcription (31). Given that Rac2 ${ }^{-/}$mice also exhibit defects in MAPK activation and IL-2 production $(46,47)$, the defective activation of MAPKs exhibited by the IBPtrap/trap $\mathrm{T}$ cells is likely to result from impaired Rho GTPase function, leading to subsequent impairments in the assembly of AP-1 complexes. Interestingly, mice with a mutation in Rasgrp1, a diacylglycerol-dependent Ras GEF involved in the TCR-mediated activation of ERK1/2 (48), also spontaneously develop a lymphoproliferative autoimmune syndrome, which is characterized by the accumulation of $\mathrm{CD} 4^{+} \mathrm{T}$ cells with an activated/memory phenotype (49). Similarly to the IBPtrap/trap mice, $T$ cells from these mice exhibit reduced proliferative responses and impairments in IL- 2 and IFN- $\gamma$ production but normal IL-4 synthesis, eventually leading toward a cytokine milieu that favors humoral responses. Thus, the defective ability of IBPtrap/trap $\mathrm{T}$ cells to efficiently activate ERK1/2 may be one of the critical molecular aberrations responsible for the disturbances exhibited by these mice.

Given that AP-1 has also been implicated in the control of IFN- $\gamma$ production (50), the molecular mechanisms employed by IBP 
to control production of this cytokine are likely to also involve defective assembly of AP-1 complexes. Intriguingly, recent studies have demonstrated that IL-12 costimulation of T cells enhances the binding of AP- 1 to the IFN- $\gamma$ promoter via STAT4 binding to AP-1 (51), suggesting a potential molecular mechanism by which exposure to IL-12 is able to rescue the TCR-mediated defects in IFN- $\gamma$ production exhibited by IBPtrap/trap $\mathrm{T}$ cells. Given the known involvement of IFN- $\gamma$ in the pathogenesis of murine lupus (52), the defects in IFN- $\gamma$ production displayed by the IBP-deficient $\mathrm{CD} 4^{+} \mathrm{T}$ cells might seem surprising. It is, however, important to note that the defective production of IFN- $\gamma$ in vitro might not be reflected by an in vivo decrease in IFN- $\gamma$ levels due to the striking increase in the number of effector/memory $\mathrm{T}$ cells observed in the aging IBP-deficient mice. The decrease in the in vitro production of cytokines nonetheless represents an important indicator that lack of IBP selectively modulates the effector program of CD4 ${ }^{+} \mathrm{T}$ cells and is likely to be accompanied by additional changes in the gene expression program of activated $\mathrm{CD}^{+} \mathrm{T}$ cells, which might render IBPtrap/trap $\mathrm{T}$ cells uniquely able to drive strong humoral responses.

Our studies have failed to reveal a major role for IBP on IL-4 production by $\mathrm{T}$ cells. Furthermore, consistent with the finding that lack of IBP affects the production of Th1-type cytokines to a greater extent than Th2-type cytokines, absence of IBP in vivo leads to the enhanced production of isotypes usually associated with Th2 responses. These findings thus differ from those of Tanaka et al., who detected an increase in Th2 cytokine production upon retroviral expression of SLAT, which was associated with an inhibition of ZAP-70 activation (25). Although the reason for these discrepancies is at present unclear, our studies do not rule out the possibility that this novel molecule plays a complex role in Th differentiation. The effect of IBP deficiency on the production of $\operatorname{IgG} 1$ and $\mathrm{IgE}$ is in striking contrast to the impaired production of these isotypes exhibited by the SWAP-70-deficient mice (23). Surprisingly, our analysis has so far failed to reveal significant enhancements in IgG1 and IgE production by IBPtrap/trap B cells in vitro. These findings, coupled with the observation that IBP deficiency did not significantly affect responses to the T cell-independent antigen NP-Ficoll, suggest that abnormalities within the $\mathrm{T}$ cell compartment play a key role in the aberrant $\operatorname{IgG} 1$ and $\operatorname{IgE}$ responses detected in these mice. The finding that IBPtrap/trap mice exhibit markedly increased IgE levels after immunization with a $\mathrm{T}$ cell-dependent antigen in alum while they display increased IgG1 production under chronic inflammatory conditions suggests that the precise outcome of the absence of IBP on the T cell/B cell collaboration can be modulated by the specific immunization/stimulatory conditions to which the mice are exposed.

Although studies have demonstrated a role for Vav and Rac1 in thymocyte selection $(53,54)$, no previous report, to our knowledge, has implicated Rho GTPases or their activators in the control of peripheral tolerance. Our studies thus provide what we believe is the first genetic evidence that these pathways may be important contributors to systemic autoimmune disorders. Furthermore, although defects in the expression of other $\mathrm{T}$ cell signaling molecules have been linked to the development of syndromes resembling lupus in mice (55), many of these models do not display the sex bias that is classically associated with human SLE. Thus, the finding that the pathophysiology exhibited by the IBP-deficient mice preferentially affects females, coupled with its location on human chromosome 6 just centromeric to the MHC locus (20), may warrant an investigation of the role of this novel molecule in SLE and other autoimmune disorders.

\section{Methods}

Mice. ES (129SvEv) cells deficient in IBP were generated by Lexicon Genetics (OmniBank), utilizing a gene-trapping strategy as previously described $(26,27)$. Integration of the gene-trapping construct occurred in the first intron of the IBP gene, downstream of the exon coding for the initiation methionine. Targeted ES cells were injected into C57BL/6 blastocysts to generate chimeric mice, which were then bred to $\mathrm{C} 57 \mathrm{BL} / 6$ mice to generate F1 offspring $(26,27)$. IBP heterozygous (+/trap) mice from the F1 generation were intercrossed to obtain IBP homozygous (trap/trap) mice. All the mice used in the experiments have a mixed genetic background between 129 and C57BL/6 and were kept under specific pathogen-free conditions. Protocols were approved by the Columbia University Institutional Animal Care and Use Committee.

Flow cytometry analysis. Single-cell suspensions from thymus, spleen, and lymph nodes were isolated, stained with fluorochrome-conjugated CD4, CD8, B220, CD3, IgM, IgD, syndecan-1, CD62L, or CD44 antibodies (BD Biosciences - Pharmingen), and analyzed by FACS. Calcium measurements were obtained by loading single-cell suspensions of lymph node cells with Fura-red and Fluo-4 (Invitrogen Corp.). Cells then were stained with APCanti-CD4 antibodies (BD Biosciences - Pharmingen) and incubated on ice with $5 \mu$ anti-CD3 $\varepsilon$ antibody; this was followed by cross-linking with goat anti-hamster Ig (Jackson ImmunoResearch Laboratories Inc.) at $37^{\circ} \mathrm{C}$. Calcium flux was measured using FACSCalibur and data analyzed using FlowJo software. Loss of mitochondrial transmembrane potential was determined by staining with Mitotracker Deep Red 633 (Invitrogen Corp.).

Histopathology and immunostaining. Tissue specimens for histopathology were fixed in formalin and embedded in paraffin or quickly frozen in OCT compound. Tissue sections were stained with H\&E and analyzed by light microscopy. Immunostaining with antibodies against syndecan-1, PNA, and IgG1 was conducted as previously published (56). Immunofluorescence analysis on frozen kidney sections was performed by staining with FITC-labeled goat anti-mouse IgG or anti-C3 (Jackson ImmunoResearch Laboratories Inc.) and specimens were analyzed with a Zeiss LSM 510 laser scanning confocal microscope.

Apoptosis assays. Purified naive $\mathrm{CD}^{+} \mathrm{T}$ cells were stimulated for 72 hours with $1 \mu \mathrm{g} / \mathrm{ml}$ anti-CD3 and IL-2. Cells were then collected, washed, and cultured in duplicate wells with $10 \mathrm{ng} / \mathrm{ml}$ of IL-2 in the presence or absence of plate-bound anti-CD3 mAbs. Twenty-four hours later, cells were collected, resuspended in hypotonic lysis buffer $(0.1 \%$ sodium citrate, $0.1 \%$ Triton- $X$, $100 \mu \mathrm{g} / \mathrm{ml} \mathrm{RNase}$, and $50 \mu \mathrm{g} / \mathrm{ml}$ propidium iodide) and analyzed by FACS. Apoptosis was determined by quantification of the sub- $\mathrm{G}_{0}$ population. For selected experiments, loss of mitochondrial transmembrane potential in cells undergoing apoptosis was determined by staining with annexin $\mathrm{V}$, DAPI, and Mitotracker Deep Red 633 (Invitrogen Corp.), followed by LSR analysis. For the SEB experiments, mice were injected i.p. with $150 \mu \mathrm{g}$ of SEB (Sigma-Aldrich) or with PBS on day 0. Peripheral blood cells collected on days $0,2,7$, and 10 were stained with antibodies to $\mathrm{V} \beta 8$ and $\mathrm{CD} 4^{+}$or to ${\mathrm{V} \beta 6^{+}}^{+}$and $\mathrm{CD}^{+}$(BD Biosciences - Pharmingen) and analyzed by FACS.

Proliferation and differentiation studies. $\mathrm{CD} 4^{+} \mathrm{T}$ cells and $\mathrm{B} 220^{+}$cells were purified by negative selection using, respectively, $\mathrm{CD}^{+}{ }^{+}$-specific $\mathrm{T}$ cell enrichment columns (R\&D Systems) and CD43 ${ }^{+}$-specific microbeads (Miltenyi Biotec). For proliferation assays, cells were cultured at $1 \times 10^{5}$ per well in 96 -well plates for 48 hours with the indicated stimuli and then pulsed with $\left[{ }^{3} \mathrm{H}\right]$ thymidine $(1 \mu \mathrm{Ci} /$ well) for 18 hours. Incorporated radioactivity was measured by scintillation counting. For in vitro Th differentiation experiments, naive $\mathrm{CD} 4^{+} \mathrm{T}$ cells were purified by negative selection using the $\mathrm{CD} 4{ }^{+} \mathrm{CD} 62 \mathrm{~L}^{\text {high }}$-specific $\mathrm{T}$ cell enrichment columns (R\&D Systems). The purity of naive $\mathrm{CD} 4^{+}$cells was routinely found to be greater than $90 \%$. We then stimulated $1 \times 10^{6} \mathrm{cells} / \mathrm{ml}$ with plate-bound anti-CD3 $(1 \mu \mathrm{g} / \mathrm{ml})$ plus anti-CD28 $(2 \mu \mathrm{g} / \mathrm{ml})$ antibodies. For Th1 skewing, IL-12 $(2 \mathrm{ng} / \mathrm{ml})$ and anti-IL-4 antibodies $(10 \mu \mathrm{g} / \mathrm{ml})$ were 
added to the primary culture. For Th2 skewing, IL-4 (10 ng/ml), anti-IFN- $\gamma$ antibodies $(10 \mu \mathrm{g} / \mathrm{ml})$, and anti-IL-12 antibodies $(10 \mu \mathrm{g} / \mathrm{ml})$ were added to the culture medium. After 7 days, cells were collected, then stimulated for 24 hours with $1 \mu \mathrm{g} / \mathrm{ml}$ anti-CD3 antibodies; supernatants were analyzed for cytokine production by ELISA (Pierce Biotechnology).

Western blotting. Lymph node T cells were stimulated with $5 \mu$ g of hamster anti-CD $3 \varepsilon \mathrm{mAbs}$ followed by cross-linking with $10 \mu \mathrm{g}$ of goat anti-hamster $\mathrm{Ig}$ for the indicated times. Whole-cell lysates were prepared as previously described (24). Activation of Lck, ZAP-70, and ERK1/2 was analyzed by Western blotting with a phosphospecific antibody against Tyr394 of Lck (29), Tyr319 of ZAP-70 (Cell Signaling Technology), and Thr202/Tyr204 of ERK1/2 (Cell Signaling Technology). Expression of c-Fos was analyzed using an antibody against c-Fos (Santa Cruz Biotechnology Inc.).

Serum Igs. Serum Ig levels from unimmunized 6-week-old mice were determined by isotype-specific ELISA (SouthernBiotech and BD Biosciences - Pharmingen). For T cell-dependent immunizations, mice were immunized with $100 \mu \mathrm{g}$ of NP-KLH alum precipitated by i.p. injection. Blood was collected on days 0,14 , and 28 after immunizations, and relative amounts of NP-specific IgM, IgG $1, I g G_{2 a}$, and $I_{g G}$ antibodies and total IgE levels determined by ELISA. Data were analyzed using 2-tailed Student's $t$ test. Values compared were means $\pm \mathrm{SD}$, with a statistical probability of $P$ as less than 0.05 being considered significant. Concentrations of autoantibodies to dsDNA and to Smith (Sm) were determined by ELISA (Alpha Diagnostic International). ANAs were detected on Hep-2 cells (Bion Enterprises Ltd.) at 1:100 serum dilution.

Immunofluorescence microscopy. A20 mouse B lymphoma cells $\left(1 \times 10^{5}\right)$ pulsed with or without $2 \mu \mathrm{g} / \mathrm{ml} \mathrm{SEE}$ (Toxin Technology Inc.) were combined with purified $\mathrm{CD} 4^{+} \mathrm{T}$ cells at a ratio of $1: 1$, centrifuged briefly, and incubated at $37^{\circ} \mathrm{C}$ for 2 minutes, 5 minutes, or 10 minutes. Conjugates settled onto poly-L-lysine-coated cover slips were fixed, permeabilized, and stained with phosphospecific antibodies to Tyr493 ZAP-70 (Cell Signaling Technology) or Tyr191 LAT (Cell Signaling Technology) or with FITC-labeled CD4, followed by staining with Alexa-Fluor 568-conjugated donkey anti-rabbit Ig (Invitrogen Corp.). Conjugates were examined by a Zeiss LSM 510 laser scanning confocal microscope with a 100×/1.3 Plan-Neofluor objective lens. FITC and Alexa-Fluor 568 (in 2 photon mode) were excited at $488 \mathrm{~nm}$ and $543 \mathrm{~nm}$, respectively, and emission was collected at $500-550 \mathrm{~nm}$ and above $585 \mathrm{~nm}$. Clustering of phosphorylated LAT and phosphorylated ZAP-70 was analyzed by acquiring a $Z$-series of 10 optical sections with an optical section thickness of approximately 1 micron. A single XY optical section of each conjugate was also acquired. The pixel density of the optical field was fixed at $512 \times 512$ pixels. The images were acquired with the maximum signal detection without any significant signal saturation. Image enhancement and analysis were performed using the public domain program NIH Image 1.6 and Adobe Photoshop 6.0. For presentation, the gray scale of images was linearly scaled (8 bit). Approximately 150 conjugates were scored visually in the absence or presence of SEE for concentration of phosphorylated ZAP-70, phosphorylated LAT, and CD4 at the cell-cell interface. Polarization was scored positive only if phosphorylated ZAP-70, phosphorylated LAT, and CD4 within the T cell were located in close proximity to the $\mathrm{B}$ cell membrane. The data were analyzed using 2-tailed Student's $t$ test. Values compared were means \pm SD from 3 independent scores of 3 different experiments, with a statistical probability of $P$ as less than 0.05 being considered significant.

Retroviral transduction and actin polymerization assays. The retroviral constructs for WT IBP, an IBP deletion mutant (IBP $\Delta 313-631)$, and a constitutively active Rac2 (Rac2G12V) (Guthrie cDNA Resource Center) were generated by cloning the appropriate coding segment into the PGC-IRES-YFP retroviral vector (57). 293T cells were cotransfected with the retroviral plasmids together with the packaging vector pCL-Eco. After 24 hours, the retroviral supernatants were harvested, supplemented with $8 \mu \mathrm{g} / \mathrm{ml}$ polybrene, and used for infection on naive $\mathrm{CD} 4^{+} \mathrm{T}$ cells that had been stimulated for 24 hours. Five days after the initial stimulation, actin polymerization studies were performed by incubating retrovirally infected $\mathrm{CD}^{+}{ }^{+} \mathrm{T}$ cells with anti-CD3 antibodies $(1 \mu \mathrm{g} / \mathrm{ml})$ for 30 minutes on ice followed by cross-linking with goat anti-hamster $\operatorname{Ig}(2 \mu \mathrm{g} / \mathrm{ml})$ for 5 minutes at $37^{\circ} \mathrm{C}$. The cells were then fixed, permeabilized, incubated with biotin-conjugated phalloidin (Invitrogen Corp.) followed by streptavidin-PE (BD Biosciences - Pharmingen) for 30 minutes, and analyzed by FACS. The histograms represent gated YFP-positive cells, and data are shown as unstimulated cells with overlay of stimulated cells.

\section{Acknowledgments}

We would like to thank C. Schindler, K. Alexandropoulous, H. Gu, and Y. Zou for their critical reading of the manuscript and discussions. The authors also thank A. Shaw for the kind gift of pY394 Lck antibodies and G. Cattoretti for help with the histopathology. The research was supported by NIH grants R01 HL-62215 and PO1 AI50514-01 and an Irma T. Hirschl Career Scientist Award to A.B. Pernis. Support to J.C. Fanzo has been provided by a Stephen I. Morse Fellowship and by NIH Training grant T32-AI07525.

Received for publication December 3, 2004, and accepted in revised form December 1, 2005.

Address correspondence to: Alessandra B. Pernis, Department of Medicine, Columbia University, 630 West 168th Street, New York, New York 10032, USA. Phone: (212) 305-3763; Fax: (212) 305-4478; E-mail:abp1@columbia.edu.

Jessica C. Fanzo's present address is: Doris Duke Charitable Foundation, New York, New York, USA.

Ayesha Siddiq's present address is: New York Medical College, Valhalla, New York, USA.

So Young Jang's present address is: Intra-cellular Therapies, New York, New York, USA.

Jessica C. Fanzo and Wen Yang contributed equally to this work.
1. Hildeman, D.A., et al. 2002. Molecular mechanisms of activated $\mathrm{T}$ cell death in vivo. Curr. Opin. Immunol. 14:354-359.

2. Green, D.R., Droin, N., and Pinkoski, M. 2003. Activation-induced cell death in T cells. Immunol. Rev. 193:70-81.

3. Goodnow, C.C., Sprent, J., de St. Groth, B.F., and Vinuesa, C.G. 2005. Cellular and genetic mechanisms of self tolerance and autoimmunity. Nature. 435:590-597.

4. Lohr, J., Knoechel, B., Nagabhushanam, V., and Abbas, A.K. 2005. T-cell tolerance and autoimmunity to systemic and tissue-restricted self-antigens.
Immunol. Rev. 204:116-127.

5. Kong, P., et al. 2003. Intrinsic T cell defects in systemic autoimmunity. Ann. N. Y. Acad. Sci. 987:60-67.

6. Lahita, R.G. 2000. Sex hormones and systemic lupus erythematosus. Rheum. Dis. Clin. North Am. 26:951-968.

7. Grimaldi, C.M., Hill, L., Xu, X., Peeva, E., and Diamond, B. 2005. Hormonal modulation of B cell development and repertoire selection. Mol. Immunol. 42:811-820.

8. Kyttaris, V., and Tsokos, G. 2004. T lymphocytes in systemic lupus erythematosus: an update. Curr. Opin. Rheumatol. 16:548-552.
9. Kane, L.P., Lin, J., and Weiss, A. 2000. Signal transduction by the TCR for antigen. Curr. Opin. Immunol. 12:242-249.

10. Fuller, C.L., Braciale, V.L., and Samelson, L.E. 2003. All roads lead to actin: the intimate relationship between TCR signaling and the cytoskeleton. Immunol. Rev. 191:220-236.

11. Bromley, S.K., et al. 2001. The immunological synapse. Annu. Rev. Immunol. 19:375-396.

12. Delon, J., and Germain, R.N. 2000. Information transfer at the immunological synapse. Curr. Biol. 10:R923-R933.

13. Bustelo, X.R. 2002. Understanding Rho/Rac 
biology in T-cells using animal models. Bioessays. 24:602-612

14. Cantrell, D.A. 2003. GTPases and T cell activation. Immunol. Rev. 192:122-130.

15. Aznar, S., and Lacal, J. 2001. Rho signals to cell growth and apoptosis. Cancer Lett. 165:1-10.

16. Zheng, Y. 2001. Dbl family guanine nucleotide exchange factors. Trends Biochem. Sci. 26:724-732.

17. Bustelo, X.R. 2001. Vav proteins, adaptors and cell signaling. Oncogene. 20:6372-6381.

18. Turner, M., and Billadeau, D.D. 2002. Vav proteins as signal integrators for multi-subunit immune-recognition receptors. Nat. Rev. Immunol. 2:476-486.

19. Schmidt, A., and Hall, A. 2002. Guanine nucleotide exchange factors for Rho GTPases: turning on the switch. Genes Dev. 16:1587-1609.

20. Gupta, S., et al. 2003. Molecular cloning of IBP, a SWAP-70 homologous GEF, which is highly expressed in the immune system. Hum. Immunol. 64:389-401.

21. Shinohara, M., et al. 2002. SWAP-70 is a guaninenucleotide-exchange factor that mediates signalling of membrane ruffling. Nature. 416:759-763.

22. Borggrefe, T., et al. 1999. Cellular, intracellular, and developmental expression patterns of murine SWAP-70. Eur. J. Immunol. 29:1812-1822.

23. Borggrefe, T., Keshavarzi, S., Gross, B., Wabl, M., and Jessberger, R. 2001. Impaired IgE response in SWAP-70deficient mice. Eur. J. Immunol. 31:2467-2475.

24. Gupta, S., et al. 2003. T cell receptor engagement leads to the recruitment of IBP, a novel guanine nucleotide exchange factor, to the immunological synapse. J. Biol. Chem. 278:43451-43459.

25. Tanaka, Y., et al. 2003. SWAP-70-like adapter of T cells, an adapter protein that regulates early TCRinitiated signaling in Th2 lineage cells. Immunity. 18:403-414

26. Zambrowicz, B.P., et al. 1998. Disruption and sequence identification of 2,000 genes in mouse embryonic stem cells. Nature. 392:608-611.

27. Zambrowicz, B., et al. 2003. Wnk1 kinase deficiency lowers blood pressure in mice: a gene-trap screen to identify potential targets for therapeutic intervention. Proc. Natl. Acad. Sci. U. S. A. 100:14109-14114.

28. Marrack, P., and Kappler, J. 2004. Control of T cell viability. Annu. Rev. Immunol. 22:765-787.

29. Holdorf, A.D., Lee, K.-H., Burack, R., Allen, P.M., and Shaw, A.S. 2002. Regulation of Lck activity by CD4 and CD28 in the immunological synapse. Nat. Immunol. 3:259-264.

30. Dong, C., Davis, R.J., and Flavell, R.A. 2002. MAP kinases in the immune response. Annu. Rev. Immunol.
20:55-72.

31. Macian, F., Lopez-Rodriguez, C., and Rao, A. 2001. Partners in transcription: NFAT and AP-1. Oncogene. 20:2476-2489.

32. Xu, L., Zhang, L., Yi, Y., Kang, H.K., and Datta, S.K. 2004. Human lupus $\mathrm{T}$ cells resist inactivation and escape death by upregulating COX-2. Nat. Med. 10:411-415.

33. Solomou, E.E., Juang, Y.T., Gourley, M.F., Kammer, G.M., and Tsokos, G.C. 2001. Molecular basis of deficient IL-2 production in T cells from patients with systemic lupus erythematosus. J. Immunol. 166:4216-4222.

34. Kyttaris, V., Juang, Y., Tenbrock, K., Weinstein, A., and Tsokos, G. 2004. Cyclic adenosine 5'-monophosphate response element modulator is responsible for the decreased expression of $\mathrm{c}$-fos and activator protein-1 binding in $\mathrm{T}$ cells from patients with systemic lupus erythematosus. J. Immunol. 173:3557-3563.

35. Tsokos, G.C., et al. 1986. Deficient gamma-interferon production in patients with systemic lupus erythematosus. Arthritis Rheum. 29:1210-1215.

36. Jury, E.C., Kabouridis, P.S., Abba, A., Mageed, R.A., and Isenberg, D.A. 2003. Increased ubiquitination and reduced expression of LCK in T lymphocytes from patients with systemic lupus erythematosus. Arthritis Rheum. 48:1343-1354.

37. Krishnan, S., et al. 2004. Alterations in lipid raft composition and dynamics contribute to abnormal $\mathrm{T}$ cell responses in systemic lupus erythematosus. J. Immunol. 172:7821-7831.

38. Juang, Y.T., et al. 2005. Systemic lupus erythematosus serum IgG increases CREM binding to the IL-2 promoter and suppresses IL-2 production through CaMKIV.J. Clin. Invest. 115:996-1005. doi:10.1172/ JCI200522854.

39. Walker, L., and Abbas, A.K. 2002. The enemy within: keeping self-reactive $\mathrm{T}$ cells at bay in the periphery. Nat. Rev. Immunol. 2:11-19.

40. Lenardo, M.J. 1991. Interleukin-2 programs mouse alpha beta T lymphocytes for apoptosis. Nature. 353:858-861.

41. Refaeli, Y., Parijs, L.V., London, C., Tschopp, J., and Abbas, A. 1998. Biochemical mechanisms of IL-2regulated Fas-mediated $\mathrm{T}$ cell apoptosis. Immunity. 8:615-623.

42. Refaeli, Y., Parijs, L.V., Alexander, S.I., and Abbas, A.K. 2002. Interferon gamma is required for activation-induced death of T lymphocytes. J. Exp. Med. 196:999-1005

43. Droin, N., and Green, D. 2004. Role of Bcl-2 family members in immunity and disease. Biochim. Biophys. Acta. 1644:179-188.

44. Strasser, A. 2005. The role of BH3-only proteins in the immune system. Nat. Rev. Immunol. 5:189-200.

45. Huppa, J.B., Gleimer, M., Sumen, C., Davis, M.M. 2003. Continuous T cell receptor signaling required for synapse maintenance and full effector potential. Nat. Immunol. 4:749-755.

46. Yu,H., Leitenberg, D., Li, B., and Flavell, R.A. 2001. Deficiency of small GTPase Rac2 affects T cell activation. J. Exp. Med. 194:915-926.

47. Li, B., et al. 2000. Role of the guanosine triphosphatase Rac2 in T helper 1 cell differentiation. Science. 288:2219-2222.

48. Dower, N.A., et al. 2000. RasGRP is essential for mouse thymocyte differentiation and TCR signaling. Nat. Immunol. 1:317-321.

49. Layer, K., et al. 2003. Autoimmunity as the consequence of a spontaneous mutation in Rasgrp1. Immunity. 19:243-255.

50. Penix, L.A., et al. 1996. The proximal regulatory element of the interferon-gamma promoter mediates selective expression in T cells. J. Biol. Chem. 271:1964-1972.

51. Park, W.R., et al. 2004. A mechanism underlying STAT4-mediated up-regulation of IFN-gamma induction inTCR-triggered T cells. Int. Immunol. 16:295-302.

52. Theofilopoulos, A.N., Koundouris, S., Kono, D.H., and Lawson, B.R. 2001. The role of IFN-gamma in systemic lupus erythematosus: a challenge to the Th1/Th2 paradigm in autoimmunity. Arthritis Res. 3:136-141.

53. Turner, M., et al. 1997. A requirement for the RhoFamily GTP exchange factor Vav in positive and negative selection of thymocytes. Immunity. 7:451-460.

54. Gomez, G., Kioussis, D., and Cantrell, D.A. 2001. The GTPase Rac- 1 controls cell fate in the thymus by diverting thymocytes from positive to negative selection. Immunity. 7:451-460.

55. King, P. 2004. Lupus-like autoimmunity caused by defects in T-cell signal transduction. Curr. Opin. Investig. Drugs. 5:517-523.

56. Falini, B., et al. 2000. A monoclonal antibody (MUM1p) detects expression of the MUM1/IRF4 protein in a subset of germinal center B cells, plasma cells, and activated T cells. Blood. 95:2084-2092.

57. Costa, G.L., et al. 2000. Targeting rare populations of murine antigen-specific $\mathrm{T}$ lymphocytes by retroviral transduction for potential application in gene therapy for autoimmune disease. J. Immunol. 164:3581-3590. 